\title{
Teacher Targets: A model for CLIL and ELF teacher education in polytechnic settings
}

\author{
Carmen Sancho Guinda \\ carmen.sguinda@upm.es \\ Universidad Politécnica de Madrid, Spain
}

\begin{abstract}
The objective of this paper is to present an alternative model for CLIL/ELF teacher education, called the Teacher Target Model, which may help hard-science teachers undertake English-medium instruction more efficiently. Conceived as a visual educational trope for changing mentalities and practices, it derives from the needs analysis of a group of polytechnic teachers who have participated in the cycles of inservice training seminars given at the Polytechnic University of Madrid since 2009. Their notions, impressions, and video-recorded performances reveal that in general they hold a monolithic conception of classroom interactions and teaching procedures, with an ensuing impoverishment of genre and language repertoires. To bridge this gap, the model proposed here cross-weaves five discursive strands converging in university lectures, namely disciplinary discourse, (meta)discourse of the medium, embedded genres, lecture phase, and teaching style, thus fostering natural communication beyond the delivery of technical content and bringing ELF instruction closer to the CLIL dynamics.
\end{abstract}

Keywords: CLIL, ELF, teacher education, polytechnic environments, language and genre repertoires

\section{THE HOLISTIC TURN IN EUROPEAN TERTIARY EDUCATION: MOVING ON TO CLIL}

One tenet of CLIL instruction, and by extension of any committed and student-centred variety of teaching, especially in a lingua franca, is that knowledge should no longer be transmitted as it has traditionally been in the conventional L1 lecture, since the focus is not solely on content but also on language and on the engagement with students (Ball and Lindsay 2013). While the language focus implies the belief that all teachers are teachers of language (Bullock 1975) and therefore their lexis, grammar, pronunciation, prosody, register and pragmatics must be as accurate and appropriate as possible, the engagement with learners embraces the need for efficacious metadiscursive and metalingual guidance to assist comprehension (Costa 2012, Dafouz 2006, Dafouz et al. 2007, Dafouz and Núñez 2010, Fortanet-Gómez and Bellés-Fortuño 2008, Mauranen 2006, 2009, Morell 2004a, Sancho Guinda 2010), a more democratic and dialogic classroom dynamics with richer forms of interaction that enable active participation and 
a realistic acquisition of the language (Coonan 2007, Foran-Storer 2007, García 2009, Guazzieri 2007, Hynninen 2012, Morell 2004b, 2007, 2009), and a series of pedagogical adjustments (Abedi 2009, De Marco and Mascherpa 2011, Echevarria and Graves 1997, Foran and Sancho 2009, Hondris et al. 2007, Shohamy 2013, van der Walt and Kidd 2013) to foster all the former and in addition autonomy, motivation, and the development of academic, interpersonal, multicultural, and even certain instrumental abilities, such as digital expertise. For over twelve years now, the Bologna Process has been driving the education offered by our European universities towards this holistic philosophy, by encouraging English-medium instruction (henceforth EMI) to stimulate mobility and introducing 'transversal skills' in the curricula to meet social demands. Thus, we could say that higher education in Europe, as Foran (2011) has noted in ESP scenarios, is on the whole undergoing a process of 'clil-ization'.

The question is: Are university content teachers prepared to face the challenge posed by these changes and clil-ize their teaching? This query invites a second one: How can we applied linguists help them achieve it? Starting from in-service training experiences at the Polytechnic University of Madrid (hereinafter UPM) - from an analysis of engineering teachers' perceptions and their recorded didactic performances - in this paper I try to find an answer in my own institution and present an alternative reworked model for EMI teacher education to bridge the gaps detected. I will first probe into the impressions and pedagogical procedures of my informants and then describe the model they have inspired. With it I intend to contribute to raising an awareness of the complexity and versatility of classroom discourse among teachers, and ultimately to changing mentalities and broadening practices in technological university settings.

\section{THE SITUATION IN MY LOCAL CONTEXT: TEACHER-TRAINING AT THE UPM}

Unlike primary and secondary schools, where a bilingual CLIL methodology has been implemented according to systematic plans, the internationalization of many universities in the Madrid region seems rather left to the capacities and motivation of staff and to the linguistic proficiency of students, assumed responsible for their familiarity (or prowess) with academic genres. At the UPM, internationalization via teacher-training is not indeed a priority and depends on the individual initiatives of 
language instructors to support their content colleagues in undertaking EMI, always welcomed and channelled through the Institute of Educational Sciences (Instituto de Ciencias de la Educación - ICE for short). One of those initiatives is the seminar "Preparación del docente para la enseñanza de contenidos técnicos en lengua inglesa dentro del EEES" ('Teacher-training for the EMI class within the EHEA'), which I have taught to over fifty engineering instructors (an average of 16 participants per course) throughout four successive editions between 2009 and 2012. The seminar sessions, which total 20 hours, cover a wide range of aspects within the linguistic and learning dimensions. The linguistic dimension gathers phonetic, intonation, lexicogrammatical, body language, and sociopragmatic guidelines. Among the latter, metadiscourse repertoires, politeness and conventions of academic genres, register features, and expressions for basic interpersonal communication skills (BICS) and cognitive academic language proficiency (CALP) - both terms coined by Cummins (1996) - are provided and explained. The learning dimension includes desirable classroom methodologies (e.g. interactive lectures, case studies, class discussions, team and project work), routines (e.g. question-answer sequences, preparatory readings) and tasks (e.g. realistic ones involving self-documentation, data representation and verbalization, problem solving and decision-making), together with their associated language. Special emphasis is laid on the phases and signalling of the lecture (Young 1994), reviewing the metadiscursive repertoire introduced in the linguistic dimension.

After a diagnostic performance (a reduced lecture up to 45 minutes long on an accessible concept from their disciplines) and a subsequent evaluation by peers and the teacher in a class discussion, the seminar participants watch different online videos of engineering lectures from the University of Stanford, available on YouTube (Stanford University Online). In pairs or small groups they take notes of teaching strategies (e.g. pace and tone, humour, asides, questions aimed at getting an answer, emphatic body language, interruptions allowed for students' questions and comments, read-outs simultaneous to blackboard calculations, etc.) to discuss their possible effectiveness in their own classes. Then, the language and teaching dimensions are taught gradually in each session by means of oral and written exercises, practical cases, discussions, and group evaluations of lecture exemplars from the MICASE corpus (The University of Michigan-English Language Institute) akin to their subject matters, given by speakers 
with a similar academic status, native or non-native, to comparable audiences (undergraduate or graduate, junior, senior or mixed), and with diverse degrees of interactivity. The diagnostic evaluation of lectures mentioned above, made by students and teacher in discussion form, is normally accomplished with a rubric negotiated beforehand, which contains the parameters from the language and learning dimensions they deem most important, and will serve later to assess a second round of volunteer peer lectures. Trainees may also look at and comment on other didactic genres in the MICASE samples, like for example colloquia, seminars, study groups or laboratory demos, to incorporate them into their methodologies, either as full sessions or as embedded genres within the lecture.

The overall objective of the seminar is, in sum, to facilitate clil-ization; that is, the expansion of learning scopes beyond content in the attendees' future classes, making them more participative, cooperative, multimodal, varied, and oriented towards language and transversal skills. To that end, it tries to instil in the participants a methodological awareness as much as a metalinguistic one because, as some CLIL researchers have remarked (Fortanet-Gómez 2013, Klaasen and Räsänen 2006), general language proficiency and fluency may be indicators of being able to function in an educational context, but do not determine the qualification of staff, who must also reflect on teaching, be flexible to involve students in active learning, and select the pedagogical strategies and techniques that best fit the class's needs. Drawing on Smith and Simpson's (1995) catalogue of teaching competencies for higher education faculty members, the course pays detailed attention to presentation and communication skills, but also to interpersonal ones and indirectly to planning issues.

\section{THE STUDY}

The study reported here combines qualitative and quantitative methods to depict the starting point of UPM instructors before committing to EMI. There are two overarching research questions: How participative do they think their teaching is? And how do their beliefs differ from their practices? In answering these two questions a third one emerges: Are the performances analysed discursively rich and engaged with student audiences? Put another way: How much do UPM content teachers resort to genre- 
embedding and with what type of rhetorical progressions? What engagement devices do they adopt? As will be seen, findings uncover a sharp mismatch between the perceptions and opinions concerning their own teaching craft and their actual performances.

\section{III.1. Method}

\section{III.1.1. Data collection and coding}

A group of 18 teachers enrolled in the seminar 'Teacher-training for the EMI class within the EHEA' volunteered to complete a brief questionnaire on their didactic strategies, their assumptions about EMI, and the main difficulties and limitations they thought they would encounter. The questions were the following:

1) What is your usual teaching dynamics? (More than one option is possible)

a. Teacher-delivered lecture

b. Team- and pair-work

c. Autonomous learning (laboratory sessions, multimedia support, reading packages prepared by the teacher, project work, guided visits)

2) Do you consider your classes participative enough?

3) What participation rate student/teacher best describes your classes?

4) Do you think that rate should be increased? If not, indicate why.

5) What do you think should be the ideal rate?

6) Mark your habitual teaching practices:

a. Start the class inductively (with familiar facts or phenomena or concrete examples to captivate the audience's interest)

b. Start the class deductively (with a general law, principle, or theory)

c. Start the class with tangible objects or authentic reports

d. Draw connections between previous contents

e. Repeat/rephrase certain points during the class

f. Ask questions to students

g. Use rhetorical questions

h. Exemplify and clarify 
i. Summarize class contents at the end

j. Anticipate contents of the current class

k. Anticipate contents of the next class

1. Let other colleagues supervise your classes

7) Do you slow down your teaching pace according to the class's level and needs? And insist more on certain parts of the syllabus?

8) What difficulties do you think you will face when teaching in English?

a. The technical vocabulary of your discipline

b. The situational vocabulary of class interaction

c. The expressions and structures to formulate hypotheses, conclusions, arguments, verbalize graphic information, evaluate the credibility of information sources, etc.

d. The expressions and structures to link ideas, emphasize relevant points, summarize, illustrate, contrast, describe, define, express attitude, etc.

e. The expressions and structures of written English to do online tutorials and corrections, conduct debate forums, or send e-mails

f. English pronunciation

g. Students' low proficiency in the English language

h. Students' mixed abilities in English

i. Assessment issues

j. The need to slow down your teaching pace to ensure the assimilation of contents

k. The elaboration of class materials

1. The adoption of adequate teaching methodologies

$\mathrm{m}$. Your aural comprehension skills to understand what students say

n. Collaboration with other colleagues to plan contents and methodology

Of the 18 instructors who completed the questionnaire, ten consented to be video-taped in their diagnostic classes. The recorded lessons, on miscellaneous topics (see Table 1), totalled 174.08 minutes and were unexpectedly short. 
Table1. Lecture corpus.

\begin{tabular}{|c|c|c|}
\hline LECTURE & LENGTH (in min) & TOPIC \\
\hline 1 & 15.54 & $\begin{array}{l}\text { Introduction to road construction } \\
\text { projects }\end{array}$ \\
\hline 2 & 17.55 & Source coding \\
\hline 3 & 14.33 & Soils compaction \\
\hline 4 & 21.20 & Sustainable energies \\
\hline 5 & 14.35 & Cartographic systems \\
\hline 6 & 16.08 & Software designs \\
\hline 7 & 18.02 & $\begin{array}{l}\text { Noise-absorbing properties of } \\
\text { reed in fitting acoustic } \\
\text { enclosures }\end{array}$ \\
\hline 8 & 16.59 & $\begin{array}{l}\mu \text {-controllers in electronic } \\
\text { systems }\end{array}$ \\
\hline 9 & 17.00 & Thermal treatment of wastes \\
\hline 10 & 21.42 & $\begin{array}{l}\text { Properties of wine and their } \\
\text { evaluation }\end{array}$ \\
\hline TOTAL & 174.08 & \\
\hline
\end{tabular}

Observations were made with the aid of a tabulated checklist template (Brown and Rodgers 2002, Dörnyei 2007) according to six interrelated parameters: Teaching style (Ogborn et al. 1996), learning boosters, structural lecture elements (adapted from Young 1994), embedded genres, academic and metadiscursive language functions (Dalton-Puffer 2007, Hyland 2005a), and engagement features (Hyland 2005b). Teaching style (i.e. visualizer, co-thinker, storyteller, verbalizer and operator) influences the insertion of genres in the lecture matrix (e.g. conversation, story or anecdote, brief case study, procedural description, problem-solving, demo or experiment, discussion, or others) and the choice of learning boosters (e.g. blackboard notes and figures, mind 
maps, PowerPoint slides, photographs, videos, the Internet, handouts, realia, and inserted tasks or demos). As for the remaining three parameters, structural elements have been simplified to facilitate analysis and confined to 'starts' (inductive, deductive or 'hands-on'/tangible), 'introduction' (either through elicitation, brainstorming, problem- or task-setting, teacher's monologues and conversations with students), 'progression' (contrastive, argumentative, descriptive and narrative - based on a chronological, cause-and-effect, or problem-solution pattern), 'recapitulation' (progressive or final), and 'closure' (visual, verbal, through a stereotyped or self-made formula, a round-off summary, or a given assignment). The academic and metadiscursive functions studied comprise goal-announcing, sequencing, stagelabelling, endophoric pointing, topic-shifting, definition, glossing or clarification, classification, exemplification/illustration, inference, enumeration, contrast, marking of relevance, and problem-solving.

Lastly, the engagement items examined, those of Hyland's (2005b) taxonomy, included the use of personal pronouns referring to the audience (as a sign of interactivity), asides, directives, expressions of shared knowledge, and questions. We should not forget, though, that metadiscourse in general, good lecture structuring, certain embedded genres such as demos, stories and anecdotes, and first-person pronouns referred to the speaker (as a sign of involvement and self-disclosure) may also be taken as engagement features. Furthermore, it is important to bear in mind that the engagement conveyed by the various kinds of questions (attending to Tsui's 1995 typology) differs in purpose: to arouse interest, expectations and reflection (rhetorical questions), to work as interactive reminders or knowledge-recall devices (display questions), and to elicit unknown information from the student (referential questions). Not every teacher knows this distinction and sometimes rhetorical and display questions are erroneously interpreted as symptoms of an interactive, dialogic lesson.

\section{III.1.2. Participants' profile}

My 18 informants were subject-matter teachers from the technical schools of Aeronautical, Agricultural, Civil, Forestry, Mining, Naval, and Telecommunications Engineering, and the faculties of Architecture and Informatics. Their mean age was 41.6 years old, with $17 \%$ of individuals in the band between $25-35,44 \%$ between 36 and 45 , 
and 39\% between 46 and 55. Their mother tongue was Spanish in all cases except two one a native speaker of German and the other one of Galician. No-one had taught in English before, despite the fact that their level of knowledge ran from B1 to $\mathrm{C} 1$ and many (13 subjects) had earned diplomas, most of them certifying high-intermediate levels of proficiency, from prestigious national and international institutions: Escuela Oficial de Idiomas, The British Council, TOEFL, and Oxford and Cambridge Examinations. When asked to evaluate their abilities in the English language on a scale from 1 to 5, where 5 stands for the highest level of command, they reported being more competent in the receptive skills (written and oral comprehension, with mean scores of 4.2 and 3.8 respectively) and less in the productive ones - written expression, with a mean score of 3.7, and oral expression, which ranked last with 3.1. This disparity between types of skills, to the detriment of oral communication, makes them feel insecure under the so-called 'native speaker fallacy' (Klaasen and Räsänen 2006), which may bias students' judgments over the pedagogical competence and credibility of their instructors (Maum 2002). Interestingly, such generalized insecurity coexists in tension with the unanimous belief that it is not their job to teach language, which is in line with the findings of other investigations into teachers' attitudes about EMI (Airey 2012).

\section{III.2. Perceptions and performances}

Perceptions and performances are closely intertwined. Teachers' notions of participation and autonomy, their assumed responsibilities, classroom routines and interpretations of student behaviour coalesce with institutional policies and shape teaching practices.

\section{III.2.1. Perceptions: Linguistic over strategic concerns}

A vast majority of respondents $(72.2 \%)$ found their classes participative enough and for slightly less than half (44.4\%) increasing students' involvement was not necessary. This conviction had been stirred up by the apparent lack of interest of senior undergraduates in extra assignments, tasks and projects, as they frequently dodge or plagiarize them to get them out of the way quickly and obtain their degree, and by the fact that junior undergraduates lack the theoretical background that would enable them to take an active part in those activities. It is somehow surprising that what informants consider 
'participative enough' is a habitual class dynamics chiefly consisting in the traditional teacher-centred lecture (see Figure 1, where the vertical axis indicates the number of teachers), accompanied by a relatively high incidence of 'autonomous learning' and little group work.

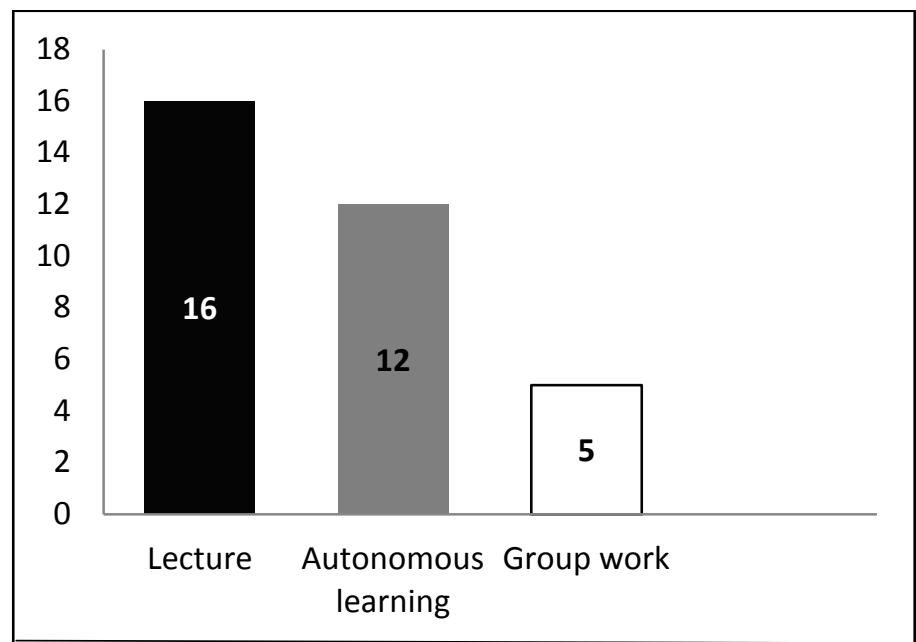

Figure 1. Usual class dynamics of UPM content teachers (self-reported).

'Autonomous learning', however, is too vague a term to draw solid conclusions about student participation and for that reason its constituents have been specified in Figure 2. In it we can observe that autonomy is not sought through before-class readings at all, and that the predominant dynamics is the laboratory session, followed by visits to companies, institutions, centres, or facilities. Because both do require the presence of some monitor or tutor, who often monopolizes talk and attention by giving instructions or even presentations and mini-lectures, the attainment of full autonomy on the students' part is questionable. In contrast, multimedia learning and project works without teacher intervention, which confront learners with content, procedural and media hurdles, are well below the other two alternatives. 


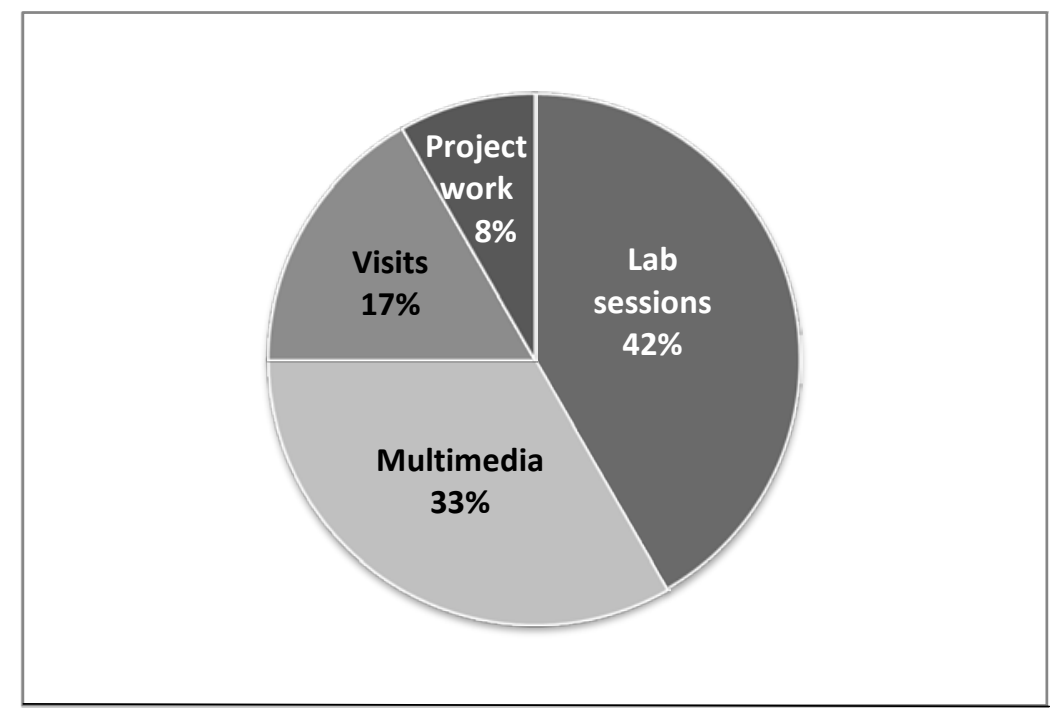

Figure 2. Breakdown of 'autonomous learning' as usual class dynamics at UPM (self-reported).

If we now turn to proportions (Figure 3), we may wonder about the notion of 'participation' UPM teachers really have. The compound percentages quantify the degree of intervention by students (the first figure, before the hyphen) and by teachers (the second figure, after the hyphen). $6 \%$ of informants, for example, rule their class time completely $(100 \%)$ with monologic lectures, leaving students no chance to participate. Actually, teachers control their lectures to a large extent (at least $75 \%$ ) in $78 \%$ of cases, and the frequency of egalitarian ratios is scant $(22 \%)$. A similar pattern was exhibited by the ideal participation rates they suggested: only $33 \%$ of them showed an accurately balanced share of control by student and teacher $(50-50 \%)$, while the rest displayed teacher quotas ranging from 60 to $80 \%$, smaller in practical subjects and bigger in theoretical or descriptive ones. 


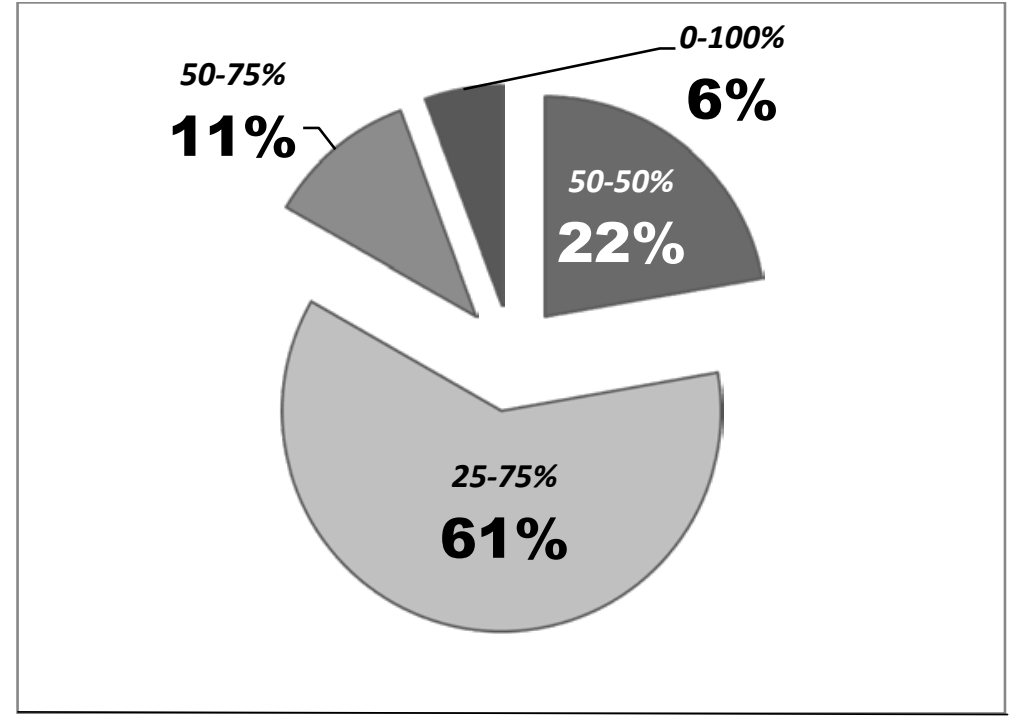

Figure 3. Habitual rate of participation (self-reported) in the lectures of content teachers at UPM.

Regarding their teaching practices, all informants coincided in relating current and previous class contents (Figure 4), and also very common were the anticipation or outlining of the content to be delivered in the present class, exemplification, illustration and clarification, and the use of questions - rhetorical and addressed to students, the latter being employed more often. Around half of the teachers advanced the content of next classes, summarized the lesson just given, repeated its major points for better assimilation, and started their delivery inductively with concrete examples or familiar facts to kindle interest and curiosity. Less customary were the deductive and hands-on or 'tangible' lesson openings (i.e. showing objects, materials or authentic documents).

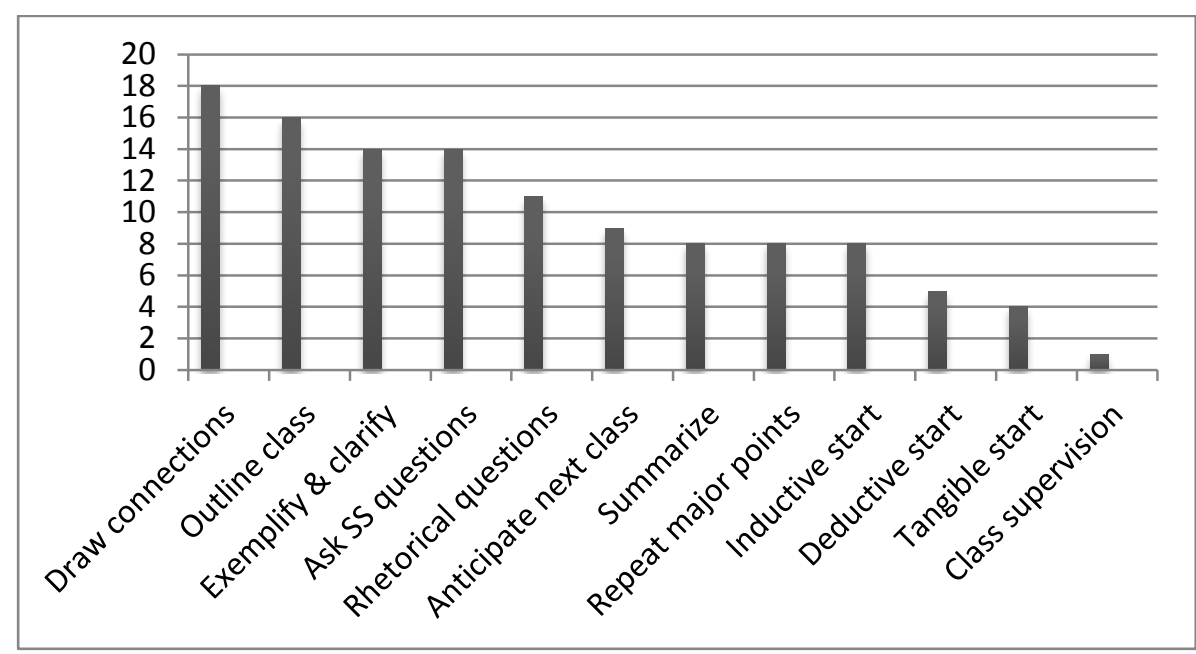

Figure 4. Habitual teaching practices (self-reported) of UPM content instructors. 
A striking finding is the slight occurrence of class supervision by colleagues (reported by only one individual) in subject matters that may be programmed and taught collaboratively by more than one teacher from the same department or by colleagues from different departments. Developing and maintaining communication and collaboration among the faculty is, as Crandall and Kaufman (2002) state, a steep challenge in content-based instruction at higher education levels, especially between content and language teachers. Firstly, because such collaborative practices are not institutionally rewarded, and secondly, because there is no one model. The instructor in question disclosed that in his case collaboration was applied to the mere supervision of content coverage.

A quick look at Figure 5 (where the horizontal axis represents the number of respondents, ' $\mathrm{T}$ ' stands for 'teacher' and 'SS' for 'students') reveals that collaboration with colleagues, class dynamics, materials and evaluation - all of them unmentioned do not worry my informants as future EMI obstacles. On the contrary, their primary concerns are, in equal measure, the language needed for class interaction (BICS) and the use of metadiscourse to link ideas and lesson stages. Their pronunciation of English and the correct expression of academic cognitive functions (CALP) are the next most important issues. Other teacher abilities, such as aural comprehension in face-to-face classes and writing repertoires to interact in virtual environments are secondary, and the impact of disciplinary vocabulary is negligible, only affecting a minority of novice staff. Methodology is certainly implicit in difficulties such as mixed-ability classes, students' low proficiency in English and the need to slow down teaching pace, but this link goes unnoticed to UPM teachers, who in a conferencing session asserted that the acquisition of BICS and CALP skills is the learner's responsibility and did not connect slowing down the teaching pace with methodological adjustments, but exclusively with repercussions on the fulfilment of the syllabus. 


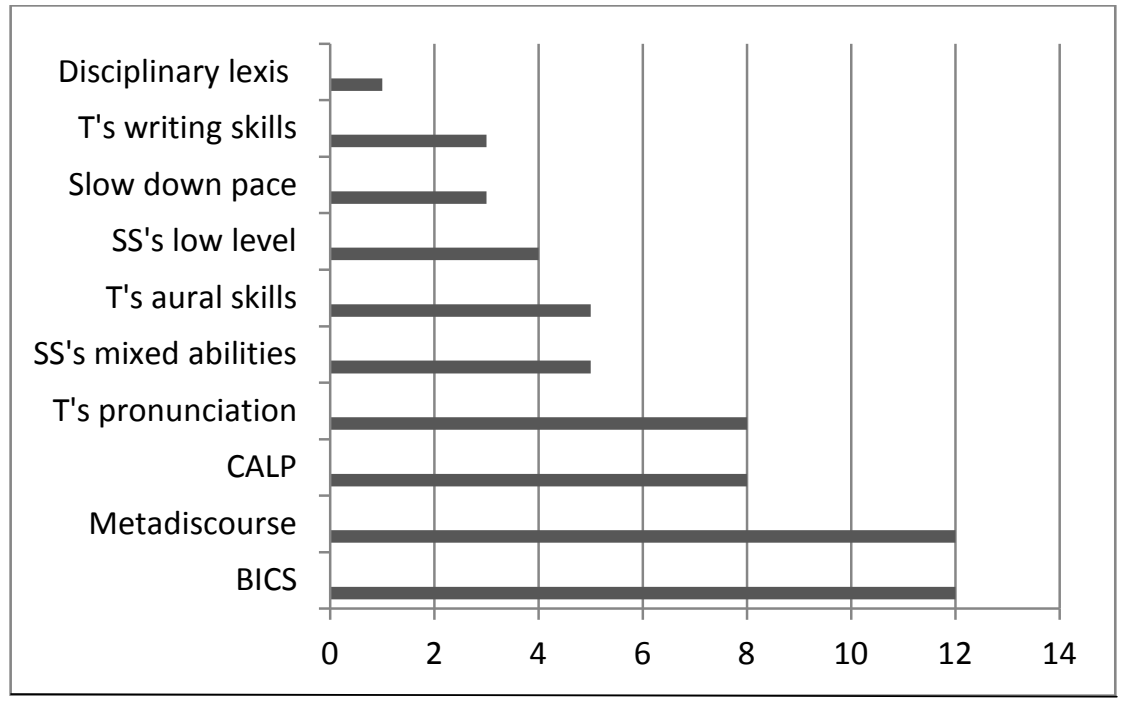

Figure 5. EMI difficulties as predicted by UPM teachers.

Neumann et al. (2002) attribute this disregard of pedagogical matters shown by hardscience instructors to their stronger commitment to research than to teaching. At the UPM, in effect, technical research and patenting are valued over teaching rankings and action research as signs of prestige and career achievements. Consequently, the belief among members of polytechnic staff that what counts is the commercialization and transmission of research, and not so much the way in which it is passed on to younger generations, is widespread.

\section{III.2.2. Performances: The inertia of low-risk choices}

For their diagnostic lessons, all volunteers opted for a lecture-centred model in a condensed conference presentation format (the average length of the talks was 17.4 min), presumably because it is a 'safe genre' on which to be evaluated, more expositive than interactive and with very narrow margins for negotiating expert roles, as the presenter holds absolute authority. In other words, they chose an updated variant of the 'chalk-and-talk' class (Mason 1994) - based on PowerPoint slide shows, a monological and prepared speech (Flowerdew 1994), and therefore little BICS, their most feared obstacle. The language they used was informal (Giménez Moreno 2008), that is to say, relaxed, with emphatic gestures, personalizations, verbal contractions, and simple connectors - let us remember that metadiscourse was their second worry after BICS when teaching in English and they logically stuck to what they already knew and avoided experimenting with variation. Most speakers were visualizers (nine out of ten 
relied heavily upon visual devices as learning boosters - see Figure 6, where the vertical axis represents the number of lectures) and just one delivered content without them, although he resorted to blackboard notes. None did web-based teaching.

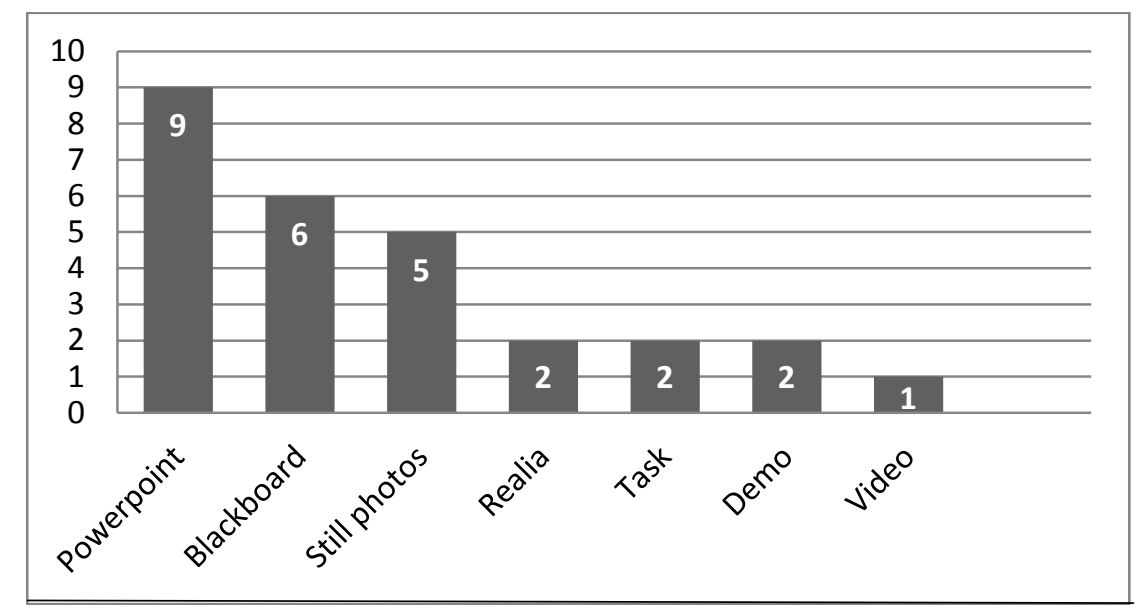

Figure 6. Use of learning boosters.

Of the nine visualizers, seven combined this style with other strategies and also became co-thinkers (embarking on a joint problem-solving task) or operators (manipulating realia brought to class or objects found in the room and used as improvised realia). There were no storytellers inserting narratives or anecdotes and only one (the teacher who did not use PowerPoint) came close to encoding knowledge in a catch-phrase or stereotyped structure (Example 1). However, it was not reiterated all throughout the lesson or in a listen-and-repeat pattern, as true verbalizers do (Ogborn et al. 1996).

(1) Ways of evaluating wine. In wine-testing there are four or five senses (digression). The rule is very simple. It is a 'four-S' rule: the first thing is SEE. So, the second is SMELL or SNIFF, the third is SWIRL, then is SIP and the last part is SUMMARIZE. (Speaker writes four capital 'Ss' and then the terms on the blackboard). [L10]

Genre-embedding was scarce and fundamentally consisted in process or procedural descriptions (Figure 7). Conversational exchanges (Example 2) took place for the most part while contextualizing the lesson, in its introductory phase, or in those lectures which, in addition to a final round of questions, the audience could spontaneously interrupt to comment on or add content and have their doubts cleared. 
(2) So, I want to ask you first how many of you know the 'Guitar Hero' game? I don't know how many of you... (one listener raises her hand) You? Do you know it?

So you know it? Have you tried it?

(Listener) I have tried it once.

Somebody else has tried it? No? What was your impression?

(Listener) Horrible.

(General laughter) [L8]

Discussions, case studies and stories were absent in every performance, and tasks and problem-solving, disguised as joint ventures due to their enunciation with the collective and inclusive pronoun 'we', were in the end led solely by the speaker, far from promoting autonomous learning.

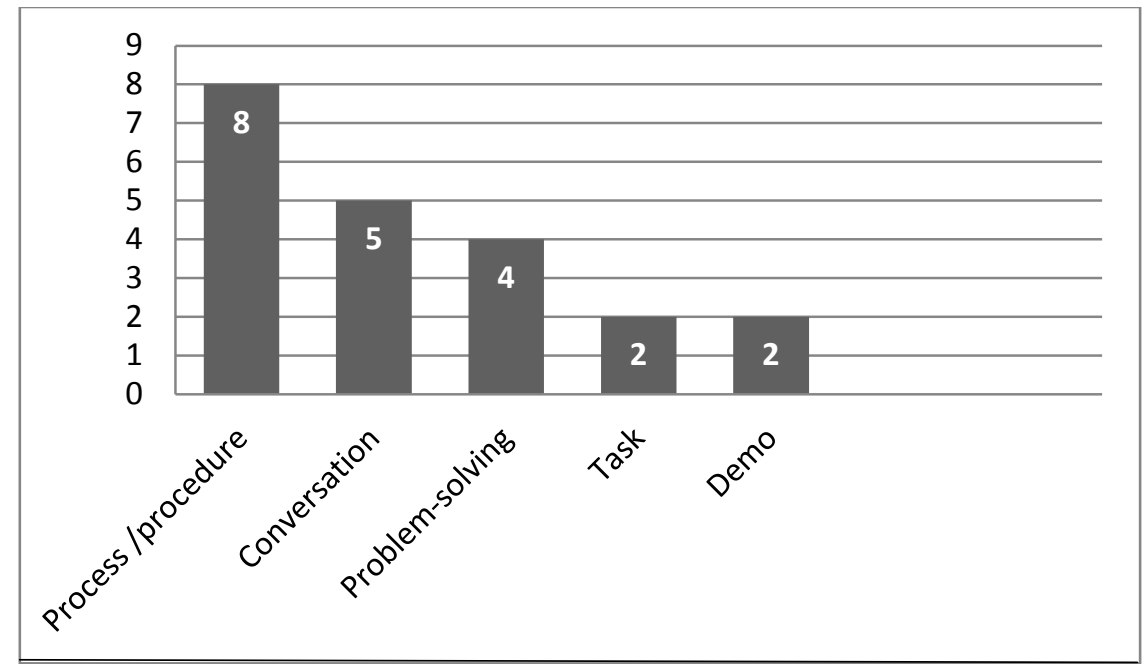

Figure 7. Lectures with embedded genres.

Structurally, the lectures were fairly complete. Introductions were made outlining the points to be touched on during the talk, in a slide devoted to that purpose (eight cases), simultaneously reading or paraphrasing them (six presenters), jotting them down on the blackboard (one lecturer), or just mentioning them (one teacher). Two speakers made use of elicitation through direct referential questions, but brainstorming, citation and quotation were untapped resources. With the exception of two lecturers, who used impersonal syntactic subjects in combination with second-person pronouns, (Example 3.a) and the first-person plural pronoun (3.b), the rest stated the contents and objective of the talk by speaking in the first-person, thus making delivery more vivid (Example 3.c). 
(3) a. The main objective of this class is that you understand the concept of thermal treatment. [L9]

b. We present three items about that. First is how the energy becomes accessible... [L4]

c. I am going to talk about wine. How it is produced and how we enjoy wine. [L10]

Contrary to the self-reported teaching habits in the questionnaire, $80 \%$ of the introductions were deductive and only two attracted the audience's attention inductively, one with projected comic strips about everyday situations using software in Lecture 6 (drawing money from a cash dispenser) and another evoking the thatched roof of the Globe Theatre in London (Lecture 7). Content progressions were in the main blended - a mixture of chronological, cause-and-effect and descriptive threads, with occasional problem-solving in five samples, whereas argumentative and contrastive structures were missing. Recapitulations were found in six lectures, which used them both in-progress, through the present tense and the solidarity structure 'we have' with an existential role (Example 4.a) and as closure of the talk, in the past and with a perfective aspect to denote completion (Example 4.b). Some lecture closures, in particular formulaic ones, were abrupt (Example 5).

(4) a. Summarizing: we have four properties which make the software complex: the complexity of the domain, the development of the software project process, we have a discrete system that makes it harder to understand than a continuous system, and the eternal flexibility of the software can make it harder to understand. [L6]

b. So, in summary: I have described the present course project, I have presented you three possibilities to implement the basic and advanced practice, and what you call 'innovative practice', where the users - sorry - the students, provide a proposal for the work - the terminal work. I also made a description of the evaluation that we want to do during the course. [L8]

(5) a. And I wish I would have more time to give you more details, but this is enough for that today. [L10]

b. And that's all, thank you everybody! [L6]

From a pedagogical standpoint, lecture structuring and signposting, and in particular summarizing, could be taken as macro-engagement devices that facilitate the processing of information. Micro-engagement ones would then be the linguistic and discursive 
items listed in Hyland's 2005a and 2005b taxonomies. As for these, observations evidenced five facts. First, that there was a comparable occurrence of all types of questions: rhetorical (four lectures, Examples 6.a-b), referential (six lectures, Examples 6.c-e), and comprehension checks (four lectures, Examples 6.f-i).

(6) a. And what is the methodology? I have used the European standard ISO 354. And what I obtained from this standard? [L7]

b. What do we mean by 'thermal processing'? Why do we want to thermally treat something? [L9]

c. Have you ever heard about this term, no? [L5]

d. Some of you know the Globe Theatre in London? [L7]

e. Do you remember the name of any white grapes varieties? [L10]

f. Have you understood what I wanted to say? [L1]

g. Is that clear, OK? [L2]

h. Does anybody have any questions? [L5]

i. Can you see from the graph? [L7]

Second, asides (found in only two lectures) did not add or clarify information but pursued complicity and rapport through humour (Examples 7.a-c).

(7) a. I hate this blackboard! [L2]

b. The game is so easy to play that even your cat can play it (slide projection of a cat near an electric guitar) [L8]

c. I'm sure that most of you will be able to distinguish between white wines and red wines, which is something quite easy, especially if you have your eyes open. [L10]

Third, directives did not abound and many were covert in the few endophorics referring to the visuals, which centred the audience's gaze (Example 8.a). There were four overt directives - three cognitive (Example 8.b), and one urging them to take immediate physical action with realia (Example 8.c).

(8) a. And this is a photograph from England. And this is another photograph from Japan. And another use you can see here is as fence, for separating houses. [L7] 
b. You have to take care about this because that is a source of mistakes. [L5]

c. Can you repeat it, please? (a certain movement with a piece of realia) [L3]

Fourth, in all lectures there was a fluctuation in pronoun use. 'I' marked the speaker role, mostly in class outlinings (Example 9.a), 'we' appeared in summaries, supposedly joint tasks, hypotheses and common perceptions and conditions (Example 9.b), and 'you' also in endophorics, in hypotheses, and in procedural descriptions (Example 9.c).

(9) a. I will give an introduction and some brief concepts. [L5]

b. Because the sensing nerves that we have are in the tongue - inside our mouth. [L10]

c. Imagine that you are in this class, OK? And that you don't have any treatment at all - no absorption treatment at all, OK? [L7]

Fifth, shared knowledge may be expressed in subtle ways, verbally (Example 10) or visually, as was the case of the projected comic strips.

(10) Probably you have heard of pyrolisis through Arguinano, who is advertising some pyrolitic ovens. [L9] (N.B. Carlos Arguiñano is a famous Spanish chef).

To conclude this analysis of performances, metadiscourse and academic functions pervaded every lecture (Figure 8), but their repertoires were somewhat poor.

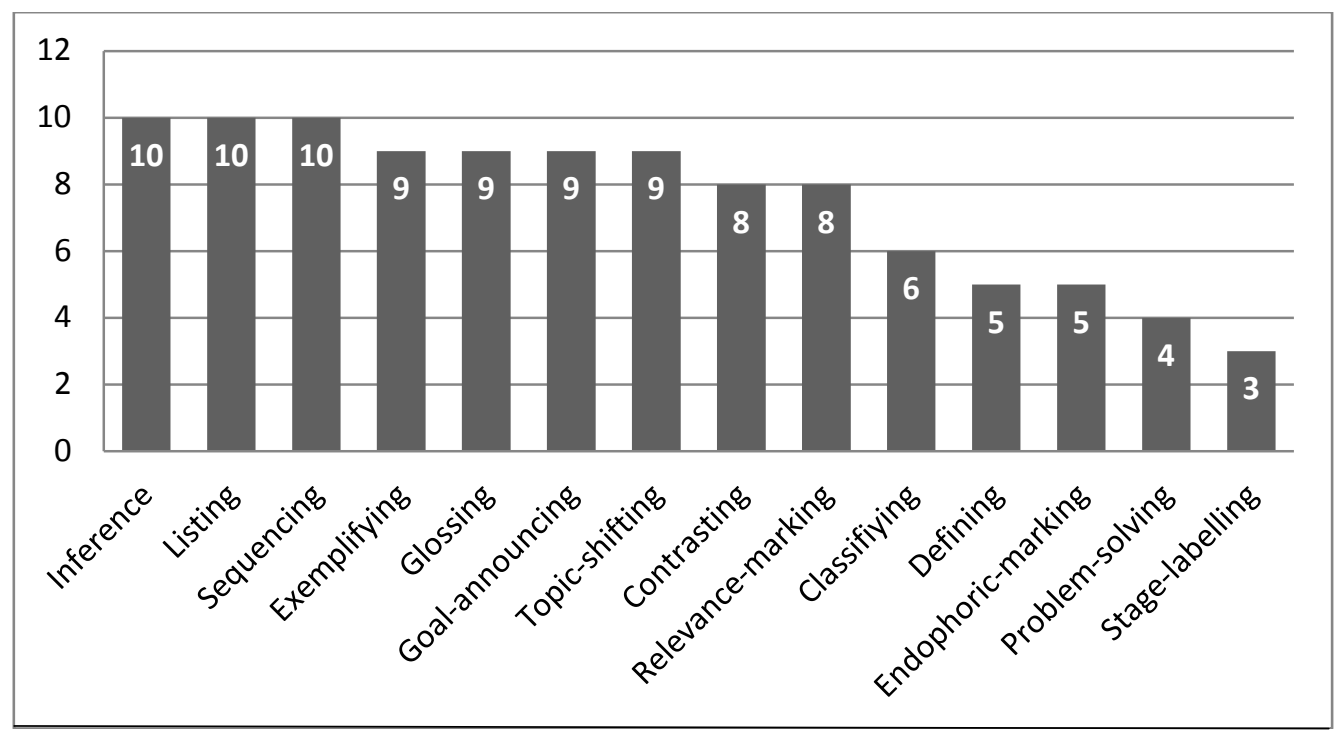

Figure 8. Recourse to key metadiscourse and CALP.

Sequencers, for example, were limited to 'first', 'second', 'then' and 'finally', the only glosses used were 'I mean'/‘this means?'/‘What does this mean?', the topic shifters 
were 'so', 'well', or regressions to the outline slide to read the next point, and 'but' and 'on the other hand' (at times misleadingly used as a topic shifter) were the only markers of contrast. This linguistic stiffness was even more patent in the expression of stagelabelling ('up to now', 'at this stage'), classification - insufficiently marked by means of 'there is/are' and 'we have' instead of expressions of (sub)division and composition such as 'divides/branches out into' or 'consists of', 'comprises', etc. - and problemsolving, which was foregrounded with the tandem of signalling nouns 'problem'/'solution'. The repertoires for endophoric-marking (even by laser-pointing), definition, exemplification, enumeration and marking of relevance were nonetheless wider. One teacher (L9) even came to highlight the importance of a concept through reiterated parallelism as emphasis (Example 11, my italics):

(11) If we heat something in the absence of oxygen, I mean, there is no oxidizing agent in the atmosphere, then, whatever we have is not going to burn, it's not going to combust, but it's going to degrade, it's going to pyrolize, it's going to decompose. So we are not going to have combustion - we are going to have pyrolisis. [L9]

Related to repertoire limitations, the building of idiolects is an added source of communication barriers. Lectures 1, 2 and 3 showed an over-recurrence of metadiscursive items with more than one function, which may easily lead to confusion: 'then' as both sequencer and inferential (Lecture 1), 'this' not followed by any noun (e.g. picture, graph, diagram, part, etc.) as an ambiguous endophoric when pointing to visuals and also as a blurry antecedent encapsulating a previous proposition (Lecture 2), or 'so' as an inferential, topic-shifter and discourse-filler (Lecture 3).

\section{III.2.3. Discussion: When versions do not quite tally}

We have seen that my informants were accurate in their perceptions of BICS, metadiscourse and CALP, which turned out to be the weak points in their performances. Likewise, their self-reported teaching practices were found in most diagnostic lessons, but their ideas of autonomy and participative interaction, two cardinal issues in contentbased instruction, were not realistic and differed notably from the stagnated didactic strategies they conducted. Due to feelings of insecurity caused by their linguistic abilities, the participants remained anchored in a genre (the monologic lecture, modernized with visuals as a conference presentation) without being aware of the huge 
pedagogical potential other genres may afford, either as matrix structures or as embeddings.

To break this inertial teaching, it is necessary to know that language and didactics go hand in hand, and so certain structural and signposting functions involve CALP and, in turn, the use of CALP may affect text structure: for instance, stage-labelling favours (or may be indicative of) summaries, while citations, quotations and deductive starts are useful tools for introductions and, some progressions, such as argumentation and problem-solution, call for CALP as well. Analogously, BICS has a bearing on structure through elicitation and brainstorming to introduce lessons and start them inductively, and in embedded tasks it may change pace or act as a closure strategy. In answer to my initial question, once teachers can cope with these implications, above phonetic inhibitions, they will be ready to meet the CLIL challenge with excellence. In the next section I suggest a model - an educational trope - for teacher-training, to help them relate and retain all the crucial aspects and resources that should be taken into account in participative EMI classes.

\section{OUTCOME: THE TEACHER-TARGET MODEL}

Taking advantage of the fact that hard-science professionals are keen visualizers, I have designed an operative visual metaphor to integrate discursive and linguistic elements and serve as a comprehensive mnemonic. Shaped like a shooting target (Figure 9), its concentric circles represent the different strands of discourse that converge in university lectures, and its crosshairs embodies the reversible discursive control, depending on the genre and the situation, by teachers or students. In a highly interactive class, students would ideally be supposed to take the lead and control the flow of the lesson (horizontal movement/axis) with their expositions, questions, comments, and peer-work exchanges. The teacher might interrupt that flow (vertical movement/axis) with observations, answers, questions, glosses, cautions, and any other necessary intervention.

This model goes beyond the applications of educational tropes proposed to date, which have been essentially descriptive of teachers' and learners' perceptions of their identity roles, the learning process, and the transmission of information, all of them aspects studied cognitively by Cameron (2003) and Cortazzi and Jin (1999), or of their impact 
on specific pedagogical areas, such as vocabulary acquisition (Littlemore 2008). It takes one step further than its antecedents (Bhatia's 2012 model for interdiscursivity in academic genres, Dafouz and Núñez's 2009 proposal for a tertiary CLIL pedagogy, and Flowerdew and Miller's 1995 cultural dimensions in L2 lectures) by viewing the lecture as a complex whole and by refining the inventory of discursive and linguistic components. Moreover, it impels teachers to plan their lessons (a CLIL must) didactically and linguistically, at least roughly (see Table 2). In participative lessons, the instructor does not need to plan every phase linguistically, just to provide keywords for presenting and monitoring tasks in those stages led by the students.

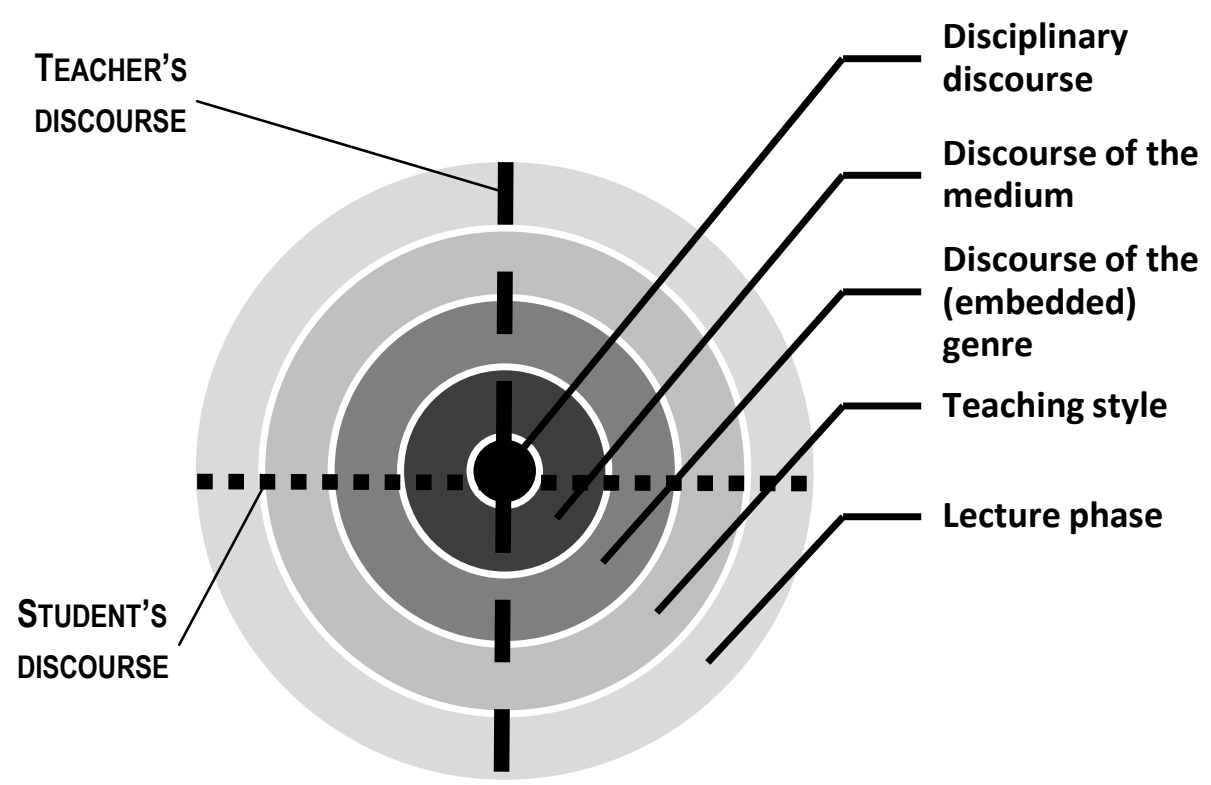

Figure 9. Converging discourses in the lecture.

Whatever the style of teaching, carrying out the teacher-target model entails providing instructors with a variety of functional repertoires (phase-, genre-, medium- and pedagogy-bound) that add to the specialized terminology of the discipline and offer a number of advantages, namely:

1) Increase the number of learning stimuli and foster occasions for natural communication other than the transmission of technical content, approaching EFL classes to CLIL.

2) Make teachers envisage the lecture as a hybrid genre in which text types (narrative, description, exposition and argumentation), genres (demos, stories, 
graph commentaries, case studies, reports, instructions, oral presentations, etc.), progressions (inductive, deductive, problem-solution, contrastive, chronological, etc.) and shifting teaching styles flow along a continuum of alternate leadership and democratic participation.

3) Make teachers realize that those lecture constituents mould one another: some disciplines and lecture phases encourage certain media and genres, which do affect the way of teaching. And conversely, in a specific subject matter and at a given point of the lecture, personal teaching preferences involve choosing some genres and media over others.

4) Make teachers plan their class dynamics: the rhetoric of the matrix and embedded genres, the discourse associated with learning boosters, and the engagement strategies with their audience.

Repertoires should include the following aspects:

LECTURE PHASE (Young 1994): Metadiscourse indispensable for discourse structuring (i.e. objectives, motivation and outline of the lesson), exemplification (including analogies, similes and metaphors), content delivery (e.g. through definitions, classifications, clarifications, explanations, hypotheses, argumentations, narratives and descriptions) and conclusion (languages of inference, recapitulation, and prediction).

TEACHING STYLE (Ogborn at al. 1996): Metadiscourse, BICS and formal and informal registers to handle different strategies and degrees of learning autonomy, control over the lesson and involvement with the students (e.g. questioning and feedback tactics, task-based teaching, project work, peer work, etc.).

Discourse OF THE (EMBEDDED) GENRE (Bhatia 2012): Moves, steps, typical metadiscourse and specialized phraseology of online genres (chats, forums, blogs, mobile learning, videos, e-portfolios, e-mail tutorials, twitters, etc.), stories, anecdotes and jokes, case studies, seminars, commentaries of graphics, demos and experiments, reports, oral presentations, instructions, etc., with their associated or admissible progressions to sequence contents (inductive, deductive, chronological, spatial, contrastive, problem-solution, known-unknown, general-particular).

DISCOURSE OF THE MEDIUM (Hewings 2012): Registers for face-to-face and online teaching, endophoric and evidential metadiscourse for visuals, expression of perception, reporting, calculation, analysis, and action verbs linked to TICs and CMC (click, cut and paste, delete, drag, log on/off, etc.). 
Table 2. Sample of lesson-phase planning.

$$
\begin{aligned}
& \text { INTERVENTIONS }=\text { TEACHER } \rightarrow \text { Intermittent description as prompt following display | } \\
& \text { and rhetorical questions to show how to use } \\
& \text { discourse features + frequent referential questions to } \\
& \text { elicit answers/description and peer (dis)agreement } \\
& \text { and feedback. } \\
& \text { (20 min) }
\end{aligned}
$$

\begin{tabular}{|c|c|c|c|c|}
\hline $\begin{array}{l}\text { SUBJECT } \\
\text { (+ lesson } \\
\text { topic) }\end{array}$ & $\begin{array}{c}\text { LECTURE } \\
\text { PHASE }\end{array}$ & $\begin{array}{l}\text { EMBEDDED } \\
\text { GENRE }\end{array}$ & MEDIA & DISCOURSE FEATURES \\
\hline $\begin{array}{l}\text { 'Aeronautical } \\
\text { alloys' } \\
\text { _ Disciplinary } \\
\text { keywords } \\
\text { (alloy, melting } \\
\text { point, plastic } \\
\text { deformation, } \\
\text { tension, yield } \\
\text { strength, etc.) }\end{array}$ & Illustration & 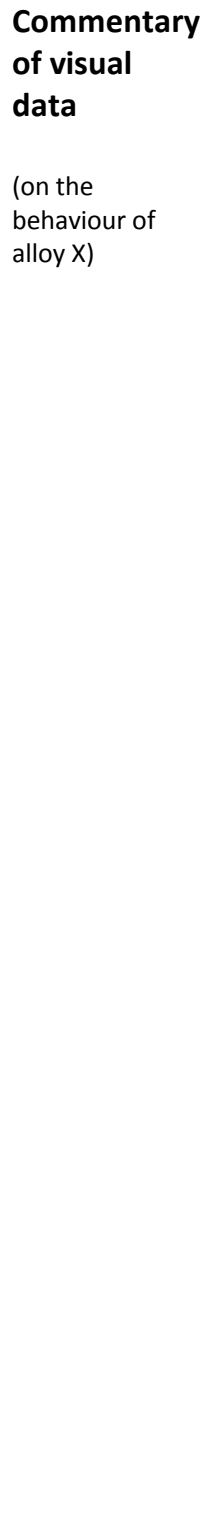 & $\begin{array}{l}\quad \text { PowerPoint } \\
\text { _Endophorics } \\
\text { (As the graph shows...) } \\
\text { _Evidentials } \\
\text { (According to the } \\
\text { diagram...) } \\
\text { _Spatial markers } \\
\text { (well over/under, } \\
\text { above/below, in the } \\
\text { foreground/background, } \\
\text { right at the top/bottom, } \\
\text { on/to the left/right, etc.) } \\
\text { _Verbs of perception } \\
\text { (see, note, notice, tease } \\
\text { out, discriminate, } \\
\text { observe, perceive, } \\
\text { appreciate, etc.) } \\
\text { _Verbs of calculation } \\
\text { (calculate, measure, } \\
\text { reckon, work out, } \\
\text { assess, evaluate, } \\
\text { estimate, etc.) } \\
\text { _Verbs of analysis } \\
\text { (examine, focus/ } \\
\text { concentrate on, } \\
\text { sort out, contrast, } \\
\text { prove, demonstrate, } \\
\text { scrutinize, etc.) }\end{array}$ & 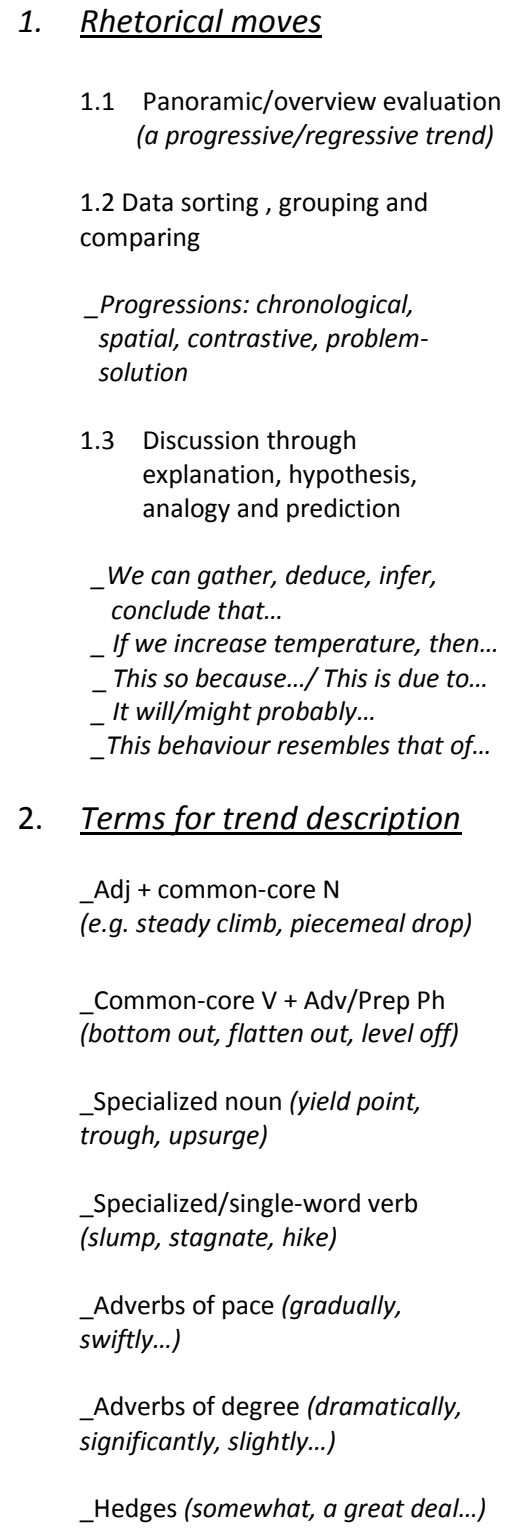 \\
\hline
\end{tabular}

STUDENT $\rightarrow$ Graph-commentary tasks, responses to teacher's questions, feedback to peers.

(30 min) 
As decisive as supplying generic, metadiscursive and lexical repertoires is the training of teachers in question/answer and feedback techniques, so that they are able to handle the axial constituent of the model to ensure that students propel and regulate lessons reasonably. The decline of teachers' control in the classroom by no means diminishes their role as architects of students' multilingual competencies, and what I have attempted with this study and its ensuing model is to reformulate it in the pursuit of more participative and creative polytechnic environments.

\section{REFERENCES}

Abedi, J. 2009. "Utilizing accommodations in assessment". In Shohamy, E. and N.H. Hornberger (Eds.) Encyclopedia of Language and Education. 2nd ed., Vol. 7, Language Testing and Assessment. Berlin: Springer, 331-347.

Airey, J. 2012. “'I don't teach language'. The linguistic attitudes of physics lecturers in Sweden”. In Smit, U. and E. Dafouz (Eds.) Integrating Content and Language in Higher Education. Gaining Insights into English-Medium Instruction at European Universities. Special Issue of AILA Review 25, 64-79.

Ball, P. and Lindsay, D. 2013. "Language demands and support for English-medium instruction in tertiary education. Learning from a specific context”. In Doiz, A., D. Lasagabaster and J.M. Sierra (Eds.) English-Medium Instruction at Universities. Global Challenges. Bristol: Multilingual Matters, 44-61.

Bhatia, V.K. 2012. "Interdiscursivity in Academic Genres". In Berkenkotter, C., V.K. Bhatia and M. Gotti (Eds.) Insights into Academic Genres. Bern: Peter Lang, 4765.

Brown, J.D. and Rodgers, T.S. 2002. Doing Second Language Research. Oxford: Oxford University Press.

Bullock, A. 1975. Bullock Report. A Language for Life. London: HMSO.

Cameron, L. 2003. Metaphor in Educational Discourse. London: Continuum.

Coonan, C.M. 2007. "How are students engaged in subject learning through the foreign language? Activities for learning in a CLIL environment”. In Marsh, D. and D. 
Wolff (Eds.) Diverse Contexts-Converging Goals. CLIL in Europe. Frankfurt am Main: Peter Lang, 153-169.

Cortazzi, M. and Jin, L. 1999. "Bridges to learning: Metaphors of teaching, learning and language". In Cameron, L. and G. Low (Eds.) Researching and Applying Metaphor. Cambridge: Cambridge University Press, 149-176.

Costa, F. 2012. "Focus on form in ICLHE lectures in Italy: Evidence from Englishmedium science lectures by native speakers of Italian”. In Smit, U. and E. Dafouz (Eds.) Integrating Content and Language in Higher Education. Gaining Insights into English-Medium Instruction at European Universities. Special Issue of AILA Review 25, 30-47.

Crandall, J. and Kaufman, D. 2002. "Content-based instruction in higher education settings: evolving models for diverse contexts". In Crandall, J. and D. Kaufman (Eds.) Content-Based Instruction on Higher Education Settings. Alexandria, Virginia: TESOL, 1-9.

Cummins, J. 1996. Negotiating Identities: Education for Empowerment in a Diverse Society. Toronto, Ontario: California Association for Bilingual Education.

Dafouz, E. 2006. "Solidarity strategies in CLIL university lectures: teachers' use of pronouns and modal verbs". VIEWZ: Vienna English Working Papers 15 (3), 915.

Dafouz, E. and Núñez, B. 2009. "CLIL in higher education: Devising a new learning landscape". In Dafouz, E. and M.C. Guerrini (Eds.) CLIL across Educational Levels: Experiences from Primary, Secondary and Tertiary Contexts. Madrid/London: Santillana Educación / Richmond Publishing, 101-112.

Dafouz, E. and Núñez, B. 2010. "Metadiscursive devices in university lectures. A contrastive analysis of L1 and L2 teacher performance". In Dalton Puffer, C., T. Nikula and U. Smit (Eds.) Language Use and Language Learning in CLIL Classrooms. Amsterdam: John Benjamins, 213-231.

Dafouz, E., Núñez, B., and Sancho, C. 2007. "Analysing stance in a CLIL university context: Non-native speaker use of personal pronouns and modal verbs". International Journal of Bilingualism and Bilingual Education 10 (5), 647-662. 
Dalton-Puffer, C. 2007. “Academic language functions in a CLIL environment". In Marsh, D. and D. Wolff (Eds.) Diverse Contexts-Converging Goals. CLIL in Europe. Frankfurt am Main: Peter Lang, 201-209.

De Marco, A. and Mascherpa, E. 2011. "Teaching Italian for Specific Purposes to Chinese students through the Moodle Platform". Presentation given at the $X$ AELFE Conference: La Investigación y la Enseñanza Aplicadas a las lenguas de Especialidad y a la Tecnología. Universitat Politècnica de València, September 57.

Dörnyei, Z. 2007. Research Methods in Applied Linguistics. Oxford: Oxford University Press.

Echevarria, J. and Graves, A. 1997. Sheltered Content Instruction. Boston, Massachusetts: Allyn \& Bacon.

Flowerdew, J. 1994. "Research of relevance to second language lecture comprehension - An overview". In Flowerdew, J. (Ed.) Academic Listening. Research Perspectives. Cambridge: Cambridge University Press, 7-29.

Flowerdew, J. and Miller, L. 1995. "On the notion of culture in L2 lectures. TESOL Quarterly 29 (3), 345-374.

Foran-Storer, D. 2007. "Teaching technical English at the tertiary and professional level: content-based cooperative learning under the CLIL umbrella”. In Marsh, D. and D. Wolff, (Eds.) Diverse Contexts-Converging Goals. CLIL in Europe. Frankfurt am Main: Peter Lang, 309-317.

Foran, D. and Sancho, C. 2009. "CLIL approaches in university Applied Science environments". In Dafouz, E. and M.C. Guerrini (Eds.) CLIL across Educational Levels: Experiences from Primary, Secondary and Tertiary Contexts. Madrid/London: Santillana Educación / Richmond Publishing, 113-124.

Foran, D. 2011. "CLIL-ized ESP: moving towards communicative competence in tertiary education - A practical demonstration". Presentation given at the $X$ AELFE Conference: La Investigación y la Enseñanza Aplicadas a las lenguas de Especialidad y a la Tecnología. Universidat Politècnica de València, September 5-7. 
Fortanet-Gómez, I. and Bellés-Fortuño, B. 2008. "The relevance of discourse markers in teacher training courses for Content and Language Integrated Learning in higher education". In Martí Arnándiz, O. and M.P. Safont Jordá (Eds.) Achieving Multilingualism: Wills and Ways. Proceedings of the First International Conference on Multilingualism (ICOM). Castelló de la Plana: Universitat Jaume I, 149-159.

Fortanet-Gómez, I. 2013. CLIL in Higher Education. Towards a Multilingual Language Policy. Bristol: Multilingual Matters.

García, O. 2009. Bilingual Education for the 21st Century. A Global Perspective. Malden, MA: Wiley-Blackwell.

Giménez Moreno, R. 2008. “Impartir la clase en inglés”. In Fortanet-Gómez. I. (Coord.) Hablar en la Universidad. Docencia e Investigación. Oviedo: Septem Ediciones, 45-81.

Guazzeri, A. 2007. "Participation in CLIL: cooperative learning in CLIL". In Marsh, D. and Wolff, D. (Eds.) Diverse Contexts-Converging Goals. CLIL in Europe. Frankfurt am Main: Peter Lang, 171-184.

Hewings, A. 2012. "Stance and voice in academic discourse across channels". In Hyland, K. and C. Sancho Guinda (Eds.) Stance and Voice in Academic Written Genres. Houndmills, Basingstoke, Hammpshire, UK: Palgrave MacMillan, 187201.

Hondris, G, Vlahavas, I. and Demetriadis, S. 2007. "Negotiation of meaning and digital textbooks in the CLIL classroom”. In Marsh, D. and D. Wolff (Eds.) Diverse Contexts-Converging Goals. CLIL in Europe. Frankfurt am Main: Peter Lang, 319-330.

Hyland, K. 2005a. Metadiscourse. Exploring Interaction in Writing. London: Continuum.

Hyland, K. 2005b. "Stance and engagement: A model of interaction in academic discourse". Discourse Studies 7 (2), 173-192.

Hynninen, N. 2012. "ICL at the micro-level: L2 speakers taking on the role of language experts". In Smit, U. and E. Dafouz (Eds.) Integrating Content and Language in 
Higher Education. Gaining Insights into English-Medium Instruction at European Universities. Special Issue of AILA Review 25, 13-29.

Klaasen, R.G. and Räsänen, A. 2006. “Assessment and staff development in higher education for English-medium instruction: A question-raising article". In Wilkinson, R. and V. Zegers (Eds.) Bridging the Assessment Gap in EnglishMedium Higher Education. Fremdsprachen in Lehre und Forschung 40. Bochum, Germany: AKS Verlag, 235-255.

Littlemore, J. 2008. "The relationship between associative thinking, analogical reasoning, image formation and metaphoric extension strategies". In Zanotto, M.S., L. Cameron and M.C. Cavalcanti (Eds.) Confronting Metaphor in Use. An Applied Linguistic Approach. Amsterdam: John Benjamins, 199-222.

Mason, A. 1994. "By dint of: Student and lecturer perceptions of lecture comprehension strategies in first-term graduate study". In Flowerdew, J. (Ed.) Academic Listening. Research Perspectives. Cambridge: Cambridge University Press, 199-218.

Maum, R. (Dec 2002). "Nonnative-English-speaking teachers in the English teaching profession". CAL Digests, document EDO-FL-02-09. 25 May 2013 $<$ http://www.cal.org/resources/digest/0209maum.html $>$

Mauranen, A. 2006. "Signalling and preventing misunderstanding in English as a lingua franca communication". International Journal of the Sociology of Language 177, 123-150.

Mauranen, A. 2009. "Chunking in EFL: Expressions for managing interaction". Intercultural Pragmatics 6 (2), 217-233.

The University of Michigan-English Language Institute. 2007. MICASE (Michigan Corpus of Academic Spoken English). 29 May 2013 $<$ http://quod.lib.umich.edu/m/micase/>

Morell, T. 2004a. "Interactive lecture discourse for university EFL". English for Specific Purposes 23 (3), 325-338.

Morell, T. 2004b. La Interacción en la Clase Magistral. Alicante: Publicaciones de la Universidad de Alicante. 
Morell, T. 2007. "What enhances EFL students' participation in lecture discourse? Student, lecturer, and discourse perspectives". Journal of English for Academic Purposes 6 (3), 222-237.

Morell, T. 2009. ¿Cómo Podemos Fomentar la Participación en Nuestras Clases Universitarias? Alcoy, Alicante: Marfil.

Neumann, R., Perry, S. and Becker, T. 2002. "Teaching and learning in their disciplinary contexts: A conceptual analysis”. Studies in Higher Education 27 (4), 405-417.

Ogborn, J., Kress, G., Martins, I. and McGillicuddy, K. 1996. Explaining Science in the Classroom. Buckingham/Philadelphia: Open University Press.

Sancho Guinda, C. 2010. "The emergent role of mind-mapping in CLIL instruction: textual cognitive resources in engineering lectures". In Morell, T., M. Aleson and M. Tabuenca (Eds.) Revista Alicantina de Estudios Ingleses (RAEI) Special Issue on Research on Teaching English 23, 83-105.

Shohamy, E. 2013. "A critical perspective on the use of English as a medium of instruction in universities". In Doiz, A., D. Lasagabaster and J.M. Sierra (Eds.) English-Medium Instruction at Universities. Global Challenges. Bristol: Multilingual Matters, 196-210.

Smith, K.S. and Simpson, R.D. 1995. "Validating teaching competencies in higher education: A national study using the Delphi method". Innovative Higher Education 19 (3), 223-233.

Stanford University Online. 29 May $2013<\underline{\text { http://online.stanford.edu/courses }}>$

Tsui, A.B.M. 1995. Introducing Classroom Interaction. London: Penguin.

Van der Walt, C. and Kidd, M. 2013. "Acknowledging academic biliteracy in higher education assessment strategies: A tale of two trials". In Doiz, A., D. Lasagabaster and J.M. Sierra (Eds.) English-Medium Instruction at Universities. Global Challenges. Bristol: Multilingual Matters, 27-43. 
Young, L. 1994. "University lectures - Macro-structures and micro-features". In Flowerdew, J. (Ed.) Academic Listening. Research Perspectives. Cambridge: Cambridge University Press, 159-176.

Received: 31 May 2013

Accepted: 26 August 2013

Cite this article as:

Sancho Guinda, C. 2013. "Teacher Targets: A model for CLIL and ELF teacher education in polytechnic settings". Language Value 5 (1), 76-106. Jaume I University ePress: Castelló, Spain. http://www.e-revistes.uji.es/languagevalue. DOI: http://dx.doi.org/10.6035/LanguageV.2012.5.5

ISSN 1989-7103

Articles are copyrighted by their respective authors 